\title{
Prediction of glomerular filtration rate maturation across preterm and term neonates and young infants using inulin as marker
}

\author{
Yunjiao Wu, ${ }^{1}$ Karel Allegaert, ${ }^{2,3}$ Robert B. Flint, ${ }^{2,4}$ Sinno H. P. Simons, ${ }^{4}$ Elke H. J. Krekels, ${ }^{1}$ \\ Catherijne A. J. Knibbe, ${ }^{1,4,5}$ and Swantje Völler ${ }^{1,4,6,7}$
}

Received 9 September 2021; accepted 30 January 2022; published online 25 February 2022

\begin{abstract}
Describing glomerular filtration rate (GFR) maturation across the heterogeneous population of preterm and term neonates and infants is important to predict the clearance of renally cleared drugs. This study aims to describe the GFR maturation in (pre)term neonates and young infants (PNA $<90$ days) using individual inulin clearance data $\left(\mathrm{CL}_{\text {inulin }}\right)$. To this end, published GFR maturation models were evaluated by comparing their predicted GFR with $\mathrm{CL}_{\text {inulin }}$ retrieved from literature. The best model was subsequently optimized in NONMEM V7.4.3 to better fit the $\mathrm{CL}_{\text {inulin }}$ values. Our study evaluated seven models and collected 381 individual $\mathrm{CL}_{\text {inulin }}$ values from 333 subjects with median (range) birthweight (BWb) 1880 g (580-4950), gestational age (GA) 34 weeks (25-43), current weight (CW) $1890 \mathrm{~g}$ (480-6200), postnatal age (PNA) 3 days (0-75), and $\mathrm{CL}_{\text {inulin }} 2.20 \mathrm{ml} / \mathrm{min}(0.43-17.90)$. The De Cock 2014 model (covariates: BWb and PNA) performed the best in predicting $\mathrm{CL}_{\text {inulin }}$, followed by the Rhodin 2009 model (covariates: CW and postmenstrual age). The final optimized model shows that GFR at birth is determined by $\mathrm{BWb}$, thereafter the maturation rate of GFR is dependent on PNA and GA, with a higher GA showing an overall faster maturation. To conclude, using individual $\mathrm{CL}_{\text {inulin }}$ data, we found that a model for neonatal GFR requires a distinction between prenatal maturation quantified by $\mathrm{BWb}$ and postnatal maturation. To capture postnatal GFR maturation in (pre)term neonates and young infants, we developed an optimized model in which PNA-related maturation was dependent on GA.
\end{abstract}

KEY WORDS: Glomerular filtration rate; Inulin; Maturation; Neonates; Preterm.

\section{INTRODUCTION}

Glomerular filtration rate (GFR) in neonates plays an important role in the clearance of drugs primarily eliminated via the kidneys. Characterizing its maturation provides a better understanding of renal function development and is helpful for the first dose selection of renally cleared drugs.

\footnotetext{
${ }^{1}$ Division of Systems Biomedicine and Pharmacology, Leiden Academic Centre for Drug Research, Leiden University, Leiden, The Netherlands.

${ }^{2}$ Department of Hospital Pharmacy, Erasmus University Medical Center, Rotterdam, The Netherlands.

${ }^{3}$ Departments of Development and Regeneration and Pharmaceutical and Pharmacological Sciences, KU Leuven, Leuven, Belgium.

${ }^{4}$ Department of Pediatrics, Division of Neonatology, Erasmus MC Sophia Children's Hospital, Rotterdam, The Netherlands.

${ }^{5}$ Department of Clinical Pharmacy, St Antonius Hospital, Nieuwegein, The Netherlands.

${ }^{6}$ Pharmacy, Leiden Academic Centre for Drug Research, Leiden University, Leiden, The Netherlands.

${ }^{7}$ To whom correspondence should be addressed. (e-mail: s.voller@lacdr.leidenuniv.nl)
}

GFR in neonates can be assessed using endogenous or exogenous markers (1-8). Among them, creatinine is the most widely used, although it is less accurate during the first days of life when its concentration reflects maternal levels (9). Moreover, creatinine undergoes passive reabsorption in the renal tubule in early infancy $(10,11)$. With regard to exogenous markers, inulin clearance $\left(\mathrm{CL}_{\text {inulin }}\right)$ is the gold standard for GFR measurement, as it is solely excreted by glomerular filtration, not resorbed, and not secreted by renal tubular cells, yet its use is associated with considerable burden and practical issues $(12,13)$. Other exogenous markers like iohexol, ${ }^{51} \mathrm{Cr}$-EDTA, and iothalamate have been evaluated in adults (14) and closely approximate inulin clearance. However, such data are limited in neonates (15, 16). Another way to determine GFR is by quantifying the clearance of drugs that are almost exclusively renally filtered. One example for this approach has been the clearance of aminoglycosides $(4,5,17,18)$. However, as aminoglycosides themselves are potentially nephrotoxic and they are mainly used in neonates with (suspected) infections, they may not represent the GFR function in non-infected neonates. 
In normal pregnancies, nephrogenesis starts from the 6th week of gestation and is normally completed by 36 weeks of gestation (19). The number of nephrons at birth increases with increasing birthweight $(\mathrm{BWb})$ and gestational age (GA) $(20,21)$. Birth introduces a transition from intrauterine to extrauterine environment, characterized by an increase in cardiac output, renal blood flow, and arterial blood pressure, and decrease in renal vascular resistance, leading to a rapid increase in GFR within the first two weeks of life $(22,23)$.

Many models have been built to characterize developmental changes for GFR. The model of De Cock et al. (4) was based solely on neonatal data and found that GFR maturation depends on both prenatal $(\mathrm{BWb})$ and postnatal (PNA) covariates. Instead of focusing on the neonatal population alone, other models tried to describe the maturation throughout childhood, using one continuous function with covariates like current bodyweight $(\mathrm{CW})$, postmenstrual age (PMA), and/or body surface area (BSA) $(2,3,5,6)$. Often, their models implicitly assume that prenatal and postnatal maturation follow the same pattern and ignore the impact of birth.

Recently, Salem et al. (1) published a GFR maturation model using inulin as marker, for individuals from 0 to 18 years of age in which the impact of both prenatal and postnatal maturation are explicitly quantified using GA, postnatal age (PNA) and CW. As a result, neonates with the same PMA show a different GFR depending on GA at birth. However, the use of their function did not result in unbiased predictions of clearance of different renally excreted drugs in preterm newborns.

With various models being published and only one model focusing on neonates, it is not clear which covariates and which functions best describe the heterogeneous pattern of GFR maturation especially in (pre)term neonates, as none of these models has been compared directly for their predictive performance of GFR in this population. This study aimed to compare the performance of available literature GFR maturation models in predicting GFR in (pre)term neonates and young infants (PNA $<90$ days), using $\mathrm{CL}_{\text {inulin }}$ data as surrogate. As a second step, a new GFR maturation model was developed based on optimization of the best literature model that would better fit the observed $\mathrm{CL}_{\text {inulin }}$ data.

\section{METHODS}

\section{Literature Search of Published GFR Maturation Models}

A literature search was conducted to retrieve models that quantified GFR maturation in both preterm and term neonates and only used demographic characteristics like $\mathrm{BWb}, \mathrm{PNA}, \mathrm{GA}, \mathrm{CW}$, height, gender, and BSA as input. The literature search was conducted in PubMed using the search term "glomerular filtration maturation neonates."

\section{Literature Search of Inulin Clearance}

Another literature search was conducted in PubMed for English studies reporting individual $\mathrm{CL}_{\text {inulin }}$ in neonates and infants up to a PNA of 90 days. The reference lists of these papers were also screened for potentially relevant articles. The search terms and flow charts are provided in the Supplementary materials. Studies reporting individual plasma or renal inulin clearance after continuous infusion were included. Subjects with major congenital anomalies, reported renal disease, or with concomitant drugs known for renal toxicity were excluded. Individual $\mathrm{CL}_{\text {inulin }}$ values and demographic information on $\mathrm{BWb}$, PNA, GA, CW, height, gender, and BSA were extracted from included papers. The clinical conditions of subjects as reported in the original papers were also collected. When inulin clearance values were published in graphs, data points were digitalized using Graph Grabber V2.0 (Quintessa.org). Data cleaning and visualization were conducted in R 4.0.2 (CRAN.R-project.org).

To be included in the dataset, each patient should at least have reported PNA values and one of the following covariates: $\mathrm{BWb}, \mathrm{GA}$, or $\mathrm{CW}$. When $\mathrm{CW}$ was missing while $\mathrm{BWb}$ and PNA were reported, $\mathrm{CW}$ was determined according to the CW growth curves versus PNA for neonates with different $\mathrm{BWb}(24,25)$. These curves were also used to calculate $\mathrm{BWb}$ from $\mathrm{CW}$ and PNA. When BWb was available while GA was not, or vice versa, the revised Fenton growth chart describing the relationship between $\mathrm{BWb}$ and $\mathrm{GA}$ was used (26). If the papers published individual sex, the revised Fenton growth chart for boys or girls was used accordingly. Otherwise, sex was randomly assigned to each patient assuming a chance of $50 \%$ for each of them. If the generated demographic values exceeded the range reported in the paper, the relevant minimum or maximum value of that paper were used instead. Unless reported, height was imputed using the equations provided by Abduljalil et al. (Eq.1) (27), and missing BSA values were imputed using the Haycock equation (Eq. 2) (28).

$$
\begin{aligned}
& \text { Height }(\mathrm{cm})=-43.205 \times \mathrm{PMA}^{2}+111.84 \times \text { PMA-9.4871 } \\
& \text { BSA }\left(\mathrm{m}^{2}\right)=\mathrm{CW}^{0.5378} \times \mathrm{Height}^{0.3964} \times 0.024265
\end{aligned}
$$

Where the BSA is the body surface area in square meters, $\mathrm{CW}$ is the current bodyweight in kilograms, height is in centimeters, and PMA is the postmenstrual age in years.

\section{Model Comparison}

The predictive performance of the included GFR maturation models was examined by comparing their predicted GFR with the individual $\mathrm{CL}_{\text {inulin values retrieved from }}$ literature (observed $\mathrm{CL}_{\text {inulin }}$ ). For this, percentage prediction error (\% $\left.\mathrm{PE}_{\mathrm{GFR}}\right)$ (Eq. 3) for each observation was calculated and plotted versus PNA to assess potential PNA-related bias of the prediction. Additionally, for predefined GA groups (< $28,28-31,32-36, \geq 37$ weeks), median $\% \mathrm{PE}_{\mathrm{GFR}}$ and root mean square percentage prediction error (\%RMSPE $\left.\mathrm{RFR}_{\mathrm{GF}}\right)$ (Eq.4) were calculated to indicate the bias and precision, respectively, of the prediction by included models in different GA groups.

$$
\% \mathrm{PE}_{\mathrm{GFR}}=\frac{\text { predicted } \mathrm{GFR}-\text { observed } \mathrm{CL}_{\text {inulin }}}{\text { observed } \mathrm{CL}_{\text {inulin }}} \times 100
$$




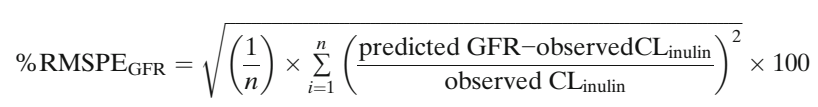

\section{Model Optimization}

To get to an optimized description of GFR in neonates and young infants, inulin clearance data were modeled using NONMEM V7.4.3 (ICON Development Solutions, Ellicott City, MD, USA), supported by Per-speaks-NONMEM (PsN) 4.9.0, and interfaced by Pirana 2.9.9. Parameters were estimated using the first-order conditional estimation with interaction $(\mathrm{FOCE}+\mathrm{I})$ method.

The most accurate literature model was used as a basis for improvement by either re-estimating the parameters, replacing the original covariates with other correlated covariates, or including other demographic covariates (BWb, PNA, CW, PMA, BSA, height) on top of the base function. If a diagnosis was reported in more than 10 subjects, this diagnosis was tested separately as binary covariate for its influence on GFR. Inter-study and inter-individual variability were tested on model parameters and assumed to be lognormally distributed with the random variable (ETA) having a mean of zero and an estimated variance of $\omega^{2}$. Inter-study variability was tested as assays and the condition of the included subjects could vary between different literature studies. For the residual variability, an additive-error model on log-transformed data was used.

Model selection for hierarchical models was based on the objective function value (OFV). A drop of more than 3.84 in OFV ( $p<0.05$; degree of freedom $=1$ ) based on likelihood ratio test was considered significant. For non-hierarchical models, the Akaike information criterion (AIC) was used (29). In addition, goodness-of-fit (GOF) plots were used for diagnostic purpose. Processing and visualization of output from NONMEM was performed in R 3.0.1 (CRAN.Rproject.org). For model evaluation, visual predictive checks (VPCs) stratified for four GA groups $(<28,28-31,32-36, \geq$ 37 weeks), based on 1000 simulations, were used.

The final optimized model was used to simulate typical GFR values versus PNA up to 60 days of five hypothetical neonates with $\mathrm{BWb}$ of $850,1500,2500,3000$, and $3600 \mathrm{~g}$, corresponding to GA of 26.1, 30.6, 35.1, 37.3, 40.2 weeks for boys and 26.5, 31.1, 35.6, 37.7, 41 for girls based on the revised Fenton growth charts (26).

\section{RESULTS}

\section{Literature Search of Published GFR Maturation Models}

In literature, we identified seven existing models (1-7) that described GFR maturation in both preterm and term neonates (Table I). Of all the included models, the De Cock 2014a (4) model was exclusively developed for the neonatal population, while the rest of the models covered the entire pediatric population.

The De Cock 2014a (4) model and the De Cock 2014b (5) model both used aminoglycoside clearance as marker for GFR. In both models, there is a fixed covariate function that describes the developmental changes of drug clearance with covariates, and a drug specific parameter, CLp, estimated for each aminoglycoside. As it was not clear which aminoglycoside's clearance best represent GFR, in the current analysis, CLp values were taken either for amikacin (De Cock 2014a), gentamicin (De Cock 2014b), or were re-estimated using collected individual $\mathrm{CL}_{\text {inulin. }}$. Therefore, for both models, two CLp values were evaluated (Table I). The reestimation of CLp using inulin clearance was conducted in NONMEM as described in the Model optimization section using the structure of the covariate function given in Table I.

\section{Literature Search of Inulin Clearance}

Data from 12 studies (30-41), reporting $381 \mathrm{CL}_{\text {inulin }}$ values from 333 patients were included in this analysis (Table II). Other than PNA, all covariates had missing values. BWb values were missing in $98(26 \%)$ out of the 381 inulin clearance observations. For those missing $\mathrm{BWb}$ values, 83 were calculated from $\mathrm{CW}$ and PNA, and the remaining 15 observations for which $\mathrm{CW}$ were not available were calculated from GA. CW was missing in 211 (55\%) observations, and were calculated from BWb and PNA. GA of 108 (28\%) observations were missing and were generated from $\mathrm{BWb}$. Both, the missing height $(n=300,79 \%)$ and BSA values $(n=255,67 \%)$ were calculated using the functions provided in the Methods. Sex was missing in most $(n=274,72 \%)$ observations. The summary of the patients' characteristics after imputation is shown in Table III.

Of the 12 studies, six reported $\mathrm{CL}_{\text {inulin }}$ in $\mathrm{ml} / \mathrm{min}$, four $(31,33,34,40)$ reported $\mathrm{CL}_{\text {inulin }}$ in $\mathrm{ml} / \mathrm{min} / 1.73 \mathrm{~m}^{2}, \mathrm{ml} / \mathrm{min} /$ $\mathrm{m}^{2}$, or $\mathrm{ml} / \mathrm{min} / \mathrm{kg}$, in which case these values were converted into $\mathrm{ml} / \mathrm{min}$ using the BSA or $\mathrm{CW}$ values provided in these studies. Two studies $(38,41)$ reported $\mathrm{CL}_{\text {inulin }}$ in a unit of $\mathrm{ml} /$ $\mathrm{min} / 1.73 \mathrm{~m}^{2}$ or $\mathrm{ml} / \mathrm{min} / \mathrm{m}^{2}$ without providing BSA (37 observations). These $\mathrm{CL}_{\text {inulin }}$ observations were converted into $\mathrm{ml} / \mathrm{min}$ using the BSA calculated by Eq. 2 . Three studies $(30,33,35)$ reported multiple measurements (2-4 times) of $\mathrm{CL}_{\text {inulin }}$ in the same subjects.

Except for one study (38) in which the clinical condition of subjects was not reported, none of the studies reported any renal disease in the included patients. Nine studies (30-33, $35-37,39,40)$ reported their patients to be either healthy or in stable condition at the time of study. Fifty patients were reported with a specific diagnosis (Table II).

Figure 1 displays the reported inulin clearance versus PNA for different GA groups on a linear scale (A) and on a $\log -\log$ scale (B). The figure shows that inulin clearance at birth is higher for higher GA, and after birth inulin clearance increases with PNA with the rate being faster for neonates with higher GA. Above 25 days postnatal age, an increased maturation rate of GFR for GA $<32$ weeks (green symbols) and a decreased maturation rate of GFR for GA > 37 weeks were observed (red symbols).

\section{Model Comparison}

Figure 2 displays the $\% \mathrm{PE}_{\mathrm{GFR}}$ of the predictions by the included GFR maturation models versus PNA per GA group. 


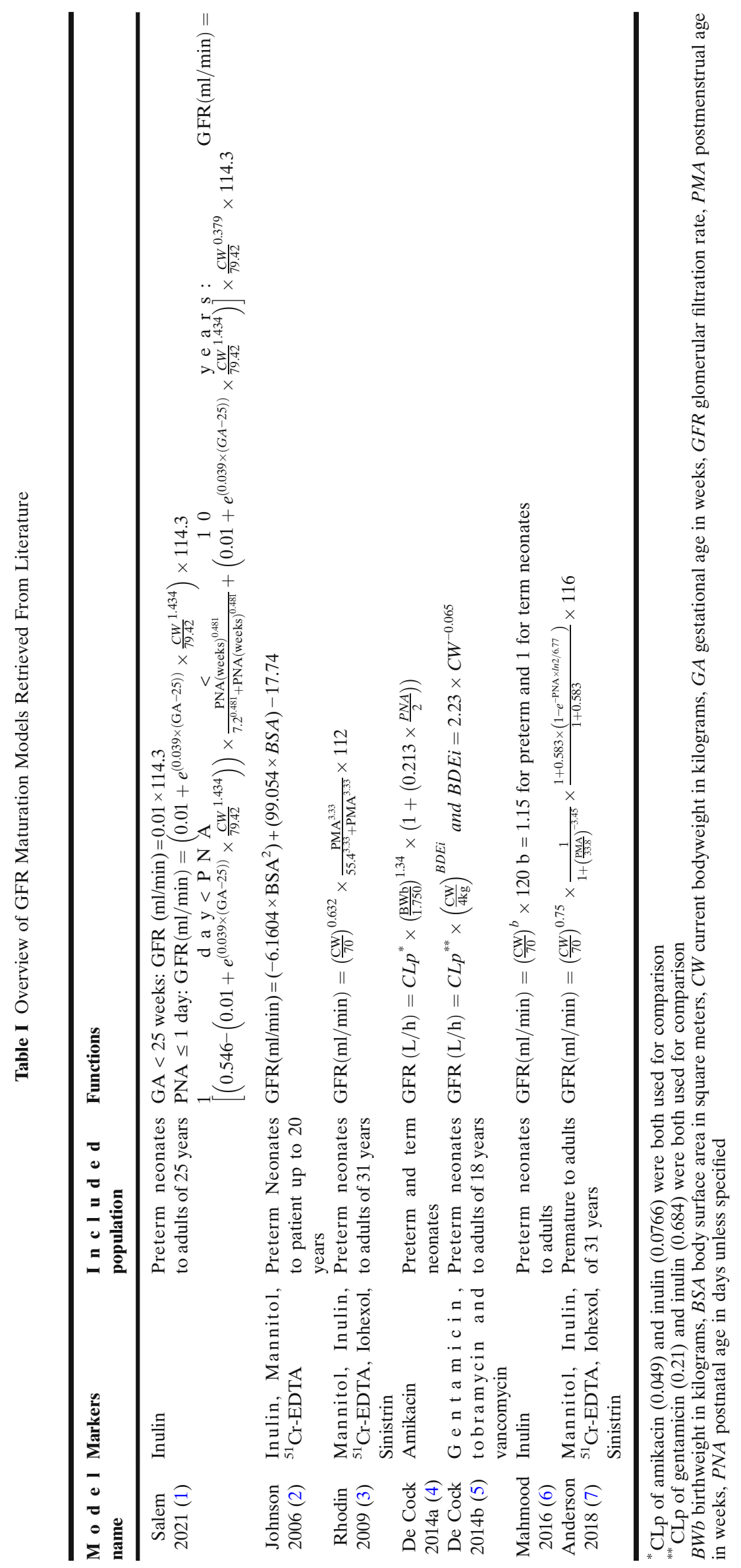




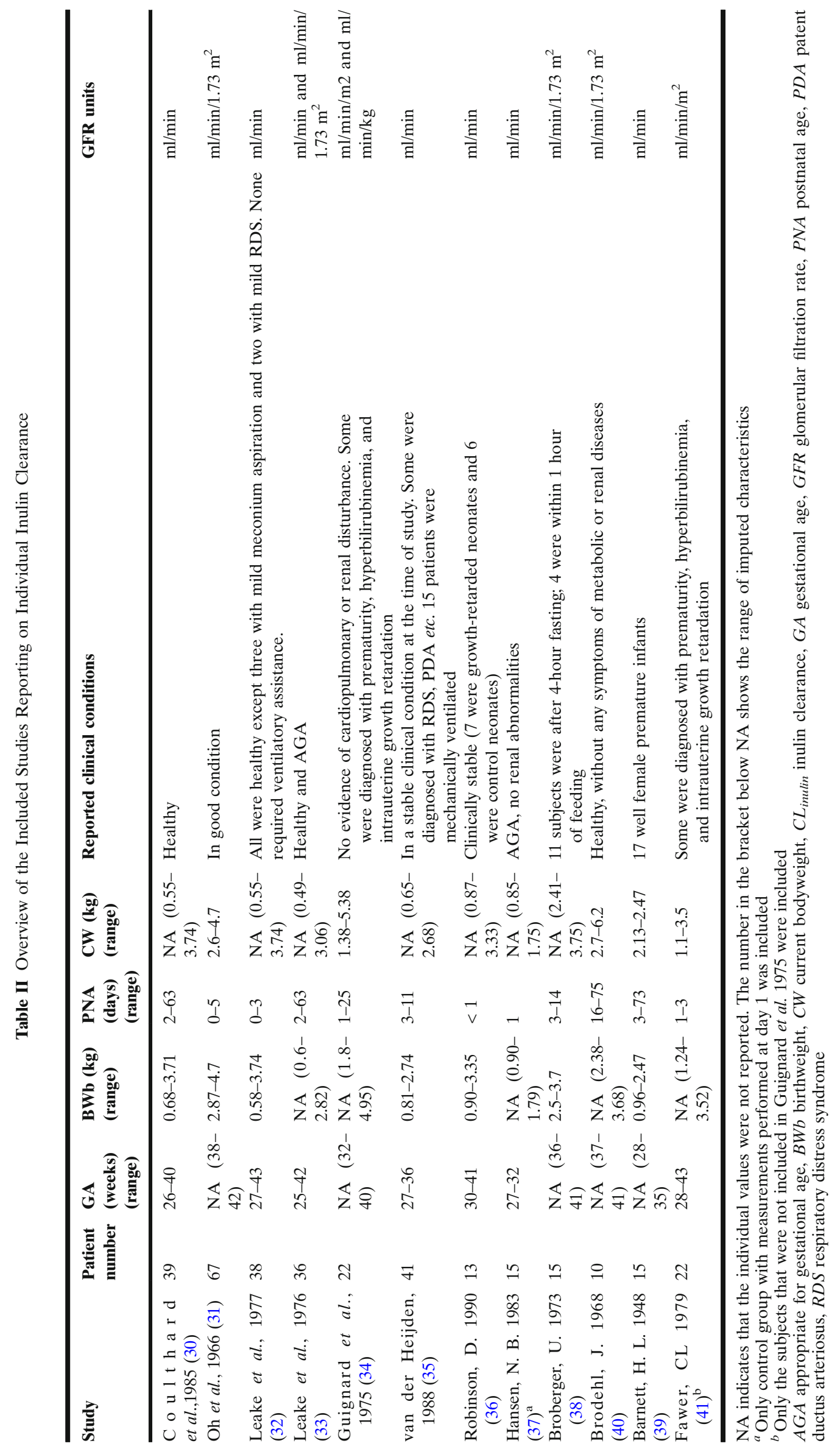


Table III Summary of the Characteristics of Patients $(n=333)$ for Which Inulin Clearance* was Reported

\begin{tabular}{ll}
\hline Patient characteristics & Median (range) \\
\hline Birthweight $(\mathrm{kg})$ & $1.88(0.58-4.95)$ \\
Gestational age (weeks) & $34.0(25.0-43.0)$ \\
Current bodyweight $(\mathrm{kg})$ & $1.89(0.48-6.20)$ \\
Postnatal age (days) & $3.0(0-75.0)$ \\
Bodyweight surface area $\left(\mathrm{m}^{2}\right)$ & $0.15(0.06-0.29)$ \\
Inulin clearance $(\mathrm{ml} / \mathrm{min})$ & $2.20(0.43-17.90)$ \\
\hline
\end{tabular}

*For detailed information of studies in which inulin clearance was extracted, see Table II

Table IV presents the $\% \mathrm{RMSPE}_{\mathrm{GFR}}$ and median $\% \mathrm{PE}_{\mathrm{GFR}}$ per GA group.

As indicated by Fig. 2 and Table IV, the De Cock 2014a model (4) with CLp estimated for inulin had the best predictive performance, followed by the Rhodin 2009 model (3). The De Cock 2014a (inulin-CLp) model generally showed an unbiased prediction of $\mathrm{CL}_{\text {inulin }}$ across PNA and GA, although there was a slight over-prediction for neonates with GA $<28$ weeks and PNA $>10$ days. Although with similar \% RMSPE ${ }_{\mathrm{GFR}}$, the Rhodin 2009 model (3) generally showed under-prediction for neonates with GA $<28$ weeks and a downward trend of $\% \mathrm{PE}_{\mathrm{GFR}}$ with increasing PNA for $\mathrm{GA} \geq 28$ weeks.

Compared to the models that use CLp of inulin, both the De Cock 2014a (4), using CLp of amikacin, and the De Cock 2014b (5), using CLp of gentamicin, underestimated CLinulin and thus have negative $\% \mathrm{PE}_{\mathrm{GFR}}$ values across GA groups. This is also confirmed by the fact that the CLp values estimated using $\mathrm{CL}_{\text {inulin }}$ for De Cock 2014a (4) model $(0.0766 \mathrm{~L} / \mathrm{h})$ and De Cock 2014b (5) $(0.684 \mathrm{~L} / \mathrm{h})$, were higher than that of amikacin $(0.049 \mathrm{~L} / \mathrm{h})$ and gentamicin $(0.21 \mathrm{~L} / \mathrm{h})$, respectively.

The Mahmood 2016 model (6) showed almost the same trend of \%PE $\mathrm{GFR}_{\mathrm{G}}$ with PNA as the Rhodin 2009 model (3), although the Mahmood 2016 model (6) had a worse prediction for term neonates. PNA-related bias was less in the Anderson 2018 model (7) compared to the Rhodin 2009 model (3), yet with generally higher \% $\mathrm{PE}_{\mathrm{GFR}}$ and

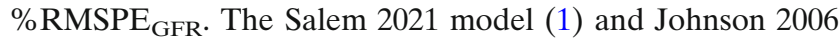
model (2) predicted adequately in term neonates, but with an obvious bias in preterm neonates.

\section{Model Optimization}

Based on the model comparison results, the De Cock 2014a (4) model using CLp for inulin was used as basis to develop the final optimized GFR maturation model for neonates and young infants. In the De Cock 2014a (4) model, GFR at birth was best described by BWb, and postnatal maturation by PNA in a linear function. After fitting to the inulin clearance data, a power function instead of linear function was found to best describe the postnatal GFR development. In addition, GA was included in the function to characterize both the steepness and shape of that PNA-related GFR development (Table V). These changes led to a reduction of OFV of 70 and AIC of 64 compared to the De Cock 2014a (4) model with inulin CLp. Replacing GA with $\mathrm{BWb}$ to describe the PNA-based GFR maturation after birth did not lead to an equal or better fit. An impact of patients' diagnosis could neither be identified with statistical significance, probably due to the lack of data on diagnosis. Inter-patient and inter-study variability were included on CLp. This optimized model was selected as final model and called the final optimized model. The final parameter estimates are listed in Table V.

The diagnostic plots for the final optimized model are provided in Fig. 3. It can be seen that the optimized model improves the over-prediction of the De Cock 2014a (inulinCLp) model for neonates $<28$ weeks GA. The VPC of the final optimized model (Fig. S1) shows generally good agreement between the observed data and the simulated confidence intervals for the medians and the 2.5th and 97.5th percentiles for all GA groups.

Figure 4 illustrates the GFR maturation predicted by the final optimized model in typical neonates with different combinations of BWb and the corresponding GA. Shortly after birth, the GFR of these neonates is determined by BWb (i.e., for $\mathrm{BWb}$ of $850 \mathrm{~g}, 1500 \mathrm{~g}$, and $3000 \mathrm{~g}$, the initial inulin clearance at
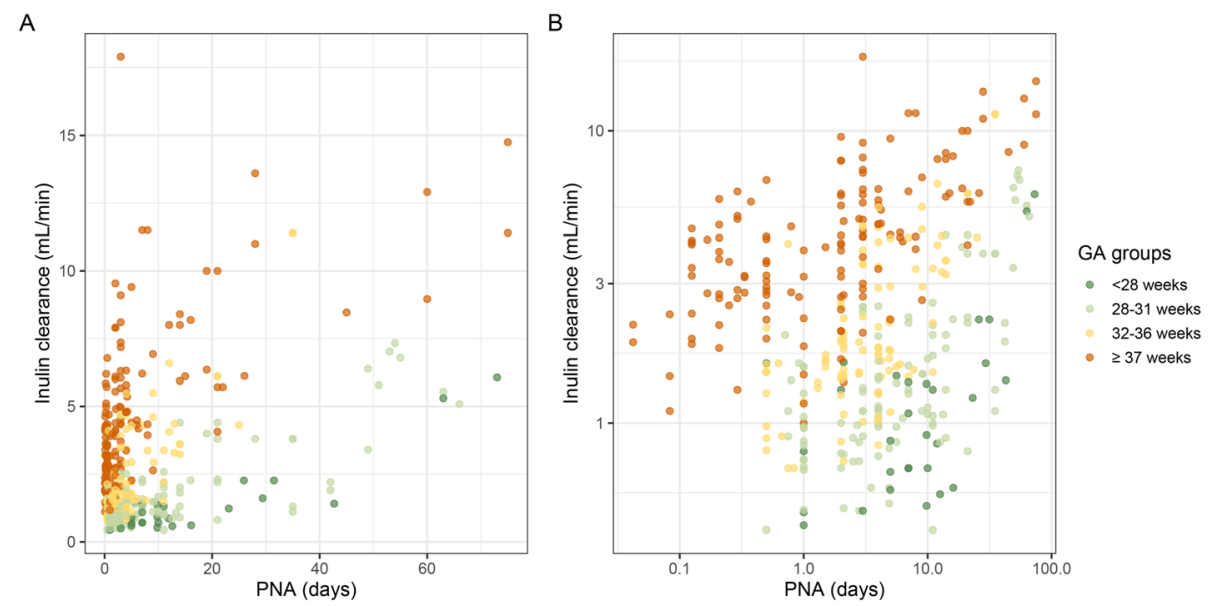

Fig. 1 Collected inulin clearance values (30-41) versus postnatal age (PNA) grouped by color for different gestational age (GA) groups on linear (A) or on log-log scale (B) 

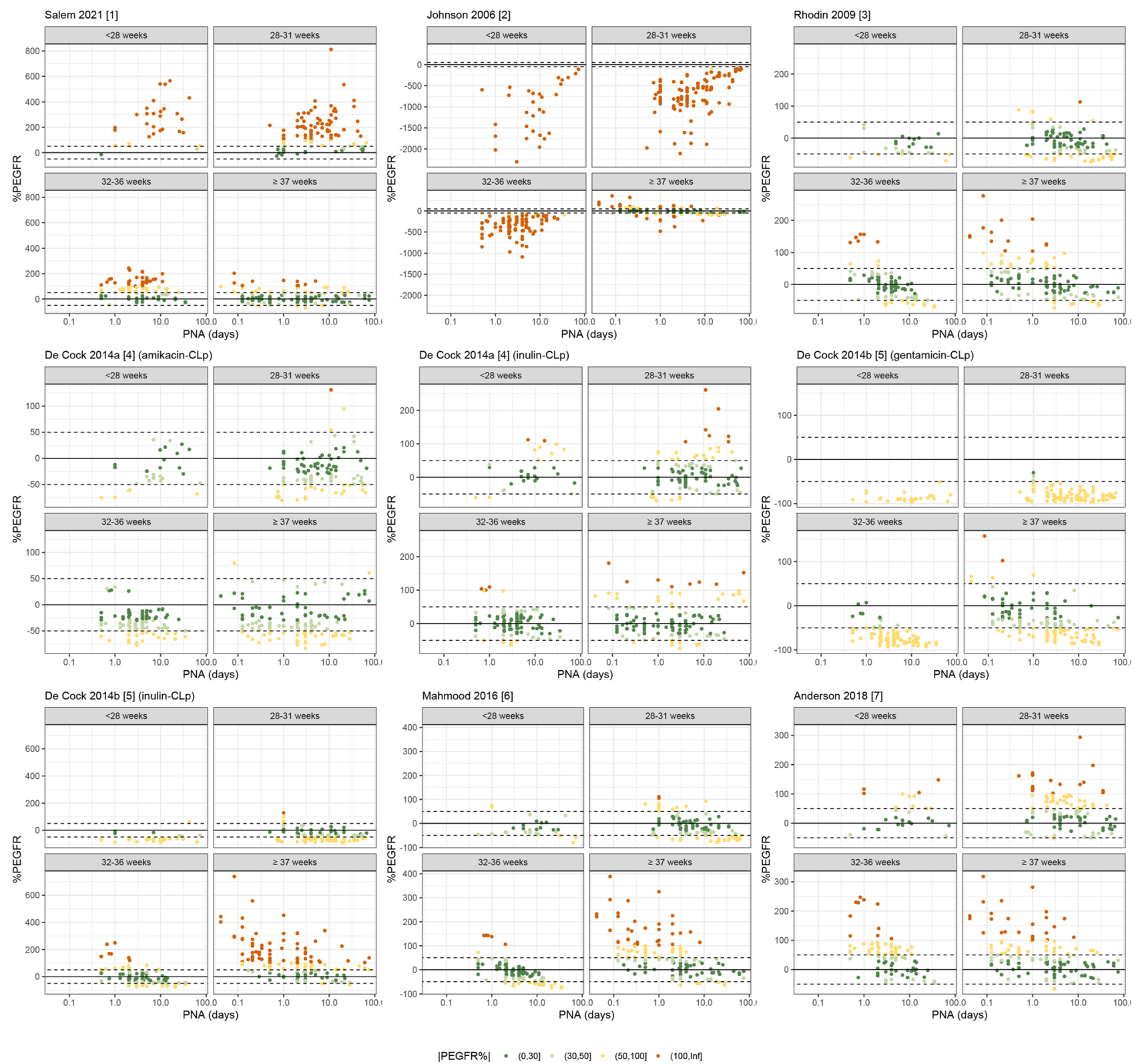

Fig. 2 Percentage prediction error $\left(\% \mathrm{PE}_{\mathrm{GFR}}\right)$ of the glomerular filtration rate (GFR) predictions by seven published models (1-7) versus postnatal age (PNA) split by different gestational ages (GA). The solid lines are the null-lines, and the dashed lines indicate $\% \mathrm{PE}$ $50 \%$ range. The $x$-axis is on log-scales

birth is $0.70,1.23,2.46 \mathrm{ml} / \mathrm{min}$, respectively). Thereafter, the maturation rate of GFR with PNA is dependent on GA. For neonates with a GA around 34 weeks, GFR increases almost linearly with PNA, while for neonates with a GA above 34 weeks, GFR increases rapidly during the first 10 days after which a slower increase is seen; for neonates with a GA under 34 weeks, GFR increases gradually at early PNA after which a more rapid increase is seen after 30 days. It took 22.3, 20.2, and 11.4 days to double the initial GFR values for neonates with a GA of 26.1, 30.6, 37.3 weeks, corresponding to neonates with a median BWb of $850 \mathrm{~g}, 1500 \mathrm{~g}$, and $3000 \mathrm{~g}$ in the Fenton growth charts (26) for boys, respectively.

\section{DISCUSSION}

Using $\mathrm{CL}_{\text {inulin }}$ as surrogate for GFR, our study evaluated different GFR maturation models from literature for their ability to predict GFR maturation in preterm and term neonates and young infants. Our evaluations show that the De Cock 2014a (4) model, for which an inulin-based CLp estimation was used, outperformed other models and had the best predictions for GFR in the neonatal population across the range of GA, BWb, and PNA studied. This model indicates that GFR increases with BWb at birth and with PNA after birth. By further improving the De Cock 2014a (4) model, we found that 
Table IV Root Mean Square Percentage Prediction Error (\%RMSPE) and Median Percentage Prediction Error (\%PE) for Glomerular Filtration Rate (GFR) Predictions by Literature Models, Stratified by GA Groups

\begin{tabular}{|c|c|c|c|c|c|c|c|c|}
\hline \multirow[t]{2}{*}{ Models } & \multicolumn{4}{|c|}{$\% \boldsymbol{R M S P E}_{G F R}$} & \multicolumn{4}{|c|}{ Median $\% P E_{G F R}$} \\
\hline & GA $<28$ & GA 28-31 & GA 32-36 & $\mathbf{G A} \geq \mathbf{3 7}$ & $\mathbf{G A}<28$ & GA $28-31$ & GA 32-36 & $\mathbf{G A} \geq \mathbf{3 7}$ \\
\hline Salem 2021 (1) & 286 & 203 & 98.9 & 51.4 & 216 & 139 & 73.5 & 3.95 \\
\hline Johnson 2006 (2) & 1218 & 807 & 379 & 97.8 & -975 & -597 & -258 & -15.6 \\
\hline Rhodin 2009 (3) & 39.1 & 41.8 & 47.8 & 63.1 & -36.3 & -19.4 & -2.03 & 5.14 \\
\hline De Cock 2014a (4) (amikacin-CLp) & 39.3 & 42.7 & 40.6 & 43.9 & -30.2 & -29.4 & -33.3 & -37.3 \\
\hline De Cock 2014a (4) (inulin-CLp) & 52.3 & 55.7 & 34.9 & 50.7 & 9.05 & 10.3 & 4.26 & -1.99 \\
\hline De Cock 2014b (5) (gentamicin-CLp) & 87.4 & 81.7 & 70.0 & 52.0 & -89.5 & -84.5 & -71.6 & -40.9 \\
\hline De Cock 2014b (5) (inulin-CLp) & 64.5 & 56.3 & 63.6 & 174 & -65.7 & -49.4 & -7.15 & 92.4 \\
\hline Mahmood 2016 (6) & 39.4 & 46.5 & 45.6 & 101 & -28.1 & -23.4 & -10.4 & 40 \\
\hline Anderson 2018 (7) & 59.0 & 74.8 & 77.8 & 83.4 & 14.5 & 33.1 & 52.0 & 32.9 \\
\hline
\end{tabular}

$G A$ gestational age (weeks)

the postnatal maturation rate of GFR is dependent on both PNA and GA. The latter is the reason for the varying postnatal GFR maturation rates that seen in Fig. 4. The optimized De Cock model can be used to predict clearance of drugs mainly eliminated by GFR, for which only a drug-specific CLp value may be required for the drug of interest.

In our study, seven models were assessed, and six of them included patients that ranged from neonates to adults. The only exception was the De Cock 2014a model (4), which only focused on neonates. This may explain why this model outperformed the other six models, as the other six models aimed to predict of renal function across the entire age-range, and were less focused on the predictions in a neonatal subpopulations, let alone to focus on the prenatal and postnatal difference in neonates. The model of Salem et al. (1) did take into account the discrepancy in GFR for neonates with the same PMA but with different GA. Their model performed well in term neonates but less well in preterm neonates. The reason for this misspecification may be that they carried out a bootstrap to generate missing individual $\mathrm{CL}_{\text {inulin }}, \mathrm{GA}$, and PNA data using reported mean, $\mathrm{SD}$, or range, which may have impacted the trend of GFR over age, especially in the event of sparse data in preterm neonates. In the Rhodin 2009 model (3), a trend of $\mathrm{PE}_{\mathrm{GFR}} \%$ with PNA was observed. This may indicate the effect of PNA on GFR for neonates even with the same PMA. Since this model predicted the GFR ontogeny in neonates and infants generally well, and connected GFR maturation function from neonates to adults, the model might be very suitable for those cases where the aim is to predict clearance in neonates based on adult values (42).

It is important to highlight that in the De Cock 2014a (4) model, the inulin-estimated CLp (0.0766) is 1.60-fold higher than the amikacin- (0.049) and gentamicin-based CLp (0.049). This means that GFR predicted in our model is higher than the typical clearance of those drugs in neonates. This difference can hardly be accounted for by the unbound fraction, because these drugs exhibit low plasma protein binding in adults, and the binding percentage should even be lower in neonates because of lower drug binding plasma protein concentrations (43). Multiple explanations then seem possible. Firstly, in the study of De Cock 2014a (4), aminoglycosides were used in sick neonates who may have been intubated, had sepsis or respiratory distress syndrome, which all have been reported to impact renal function (23, 44). Although some subjects included in our study were also sick and intubated, this number was small and our study could not identify a statistically significant impact of them on GFR maturation. Secondly, co-medications in De Cock et al. (4) population involved non-steroidal anti-inflammatory drugs (NSAIDs). This could hamper GFR, and aminoglycosides itself are also nephrotoxic $(23,44)$. However, the impact of the co-medication may not be that important as the effect of ibuprofen was accounted for in the original De Cock 2014a (co-medication of ibuprofen lead to a decrease of drug clearance by $16 \%$ ) (18). Thirdly, the difference may indicate that reabsorption processes at the level of the renal tubular cells are involved in the renal clearance of aminoglycosides. This phenomenon has been proven in both rabbits and human studies, which showed that the GFR is higher than clearance of aminoglycosides within the same population (45, 46). Still, more research is needed to identify the exact cause.

In the optimized model, prenatal maturation of GFR represented by inulin clearance was found to be determined by $\mathrm{BWb}$. This is consistent with an autopsy study of Hughson et al. (47), who found a linear relationship between the total number of glomeruli and $\mathrm{BWb}$, and predicted an increase of 257,426 glomeruli per kilogram increase in birthweight. Compared to $\mathrm{BWb}$, GA was found to be a less suitable predictor for the prenatal GFR maturation in our model development. This is not counterintuitive as infants with asymmetric or type II intrauterine growth retardation were shown to have lower nephron numbers than controls at similar gestational ages $(20,48)$. After birth, rapid changes in GFR occur and in our study GFR was shown to increase with PNA at different rates dependent on GA. Similarly, studies based on creatinine clearance have found that the rate of postnatal GFR increase is less marked in the most premature infants compared with term neonates, and this difference could persist during the first month of life (49-51).

By defining prenatal and postnatal maturation using different covariates, our study indicates that prenatal and postnatal GFR maturation indeed follows different maturation patterns. The different patterns between prenatal and 
Table V Function and Parameter Estimates of Final Optimized Model

\begin{tabular}{ll}
\hline \multicolumn{1}{l}{ Final optimized model } \\
\hline Function & $G F R=C L p \times\left[\frac{B W b}{1.75}+\left(\frac{G A}{34}\right)^{a} \times b \times\left(\frac{P N A}{2}\right)^{\left(\frac{G A}{34}\right)^{c}}\right]$ \\
Parameters & \\
CLp & $0.086(3 \%)$ \\
a & $9.99(8 \%)$ \\
b & $0.154(12 \%)$ \\
c & $-1.71(15 \%)$ \\
Inter-study variability on CLP & $19.2 \%(23 \%)[8 \%]$ \\
Inter-patient variability on CLP & $31.5 \%(5 \%)[11 \%]$ \\
Residual variability & $0.0284(18 \%)[45 \%]$ \\
\hline
\end{tabular}

$B W b$ birthweight in kilograms, $C L p$ drug-specific parameters, $G A$ gestational age (weeks), $P N A$ postnatal age (days)

postnatal renal maturation have an anatomic correlate, as proved by Sutherland et al. (52), who conducted an autopsy study comparing the kidneys from preterm neonates and stillborn gestational controls of similar postconceptional age (24 to 38 weeks). They found that preterm neonates exhibited accelerated postnatal renal maturation compared with postconceptional age-matched still-born controls. In addition, they observed that preterm kidneys had a greater percentage of morphologically abnormal glomeruli compared to controls, which might explain why preterm neonates showed a slower GFR maturation and consistently lower GFR than term neonates in the first 2 months after birth
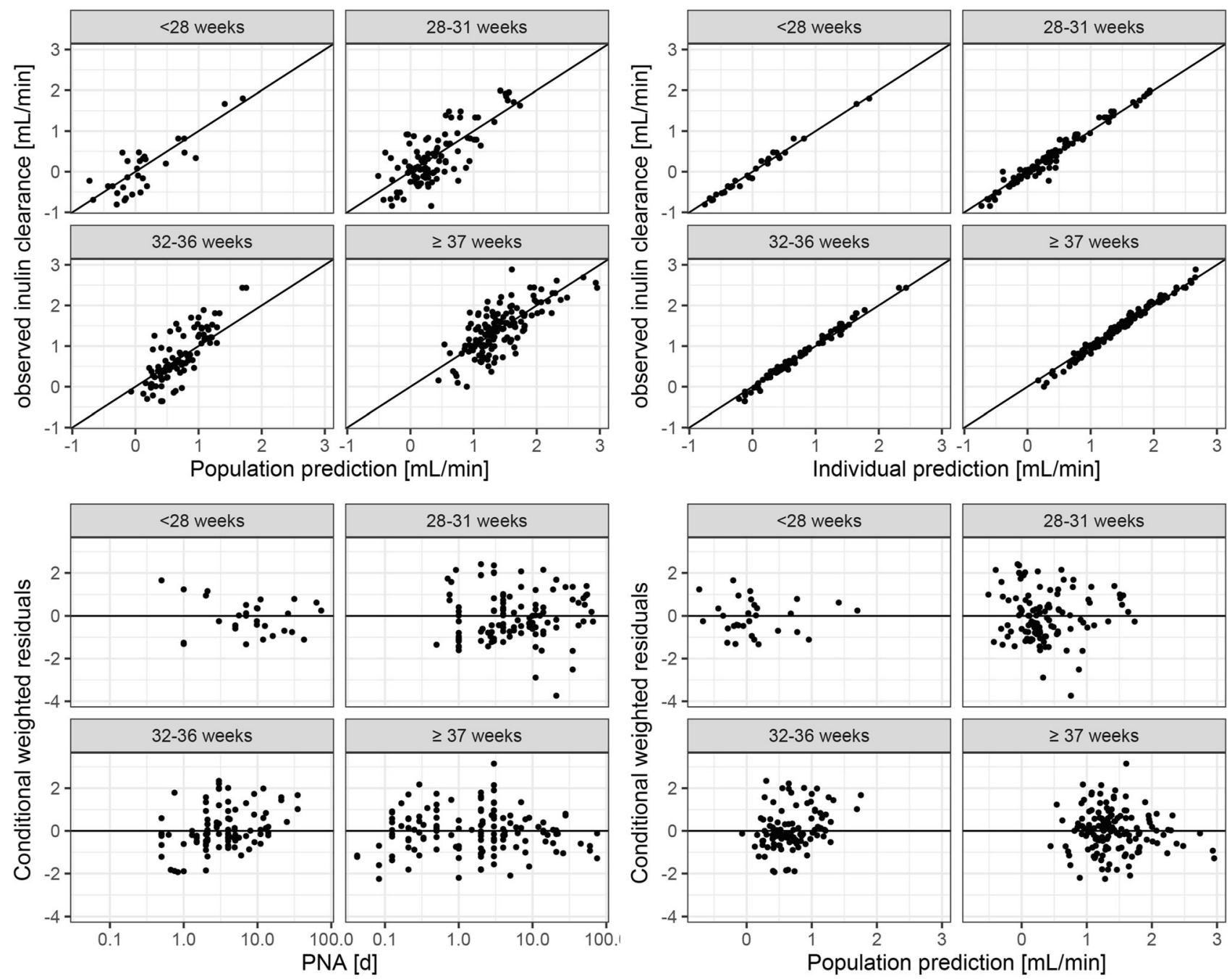

Fig. 3 Goodness of fit plots for the final optimized model grouped by gestational age 


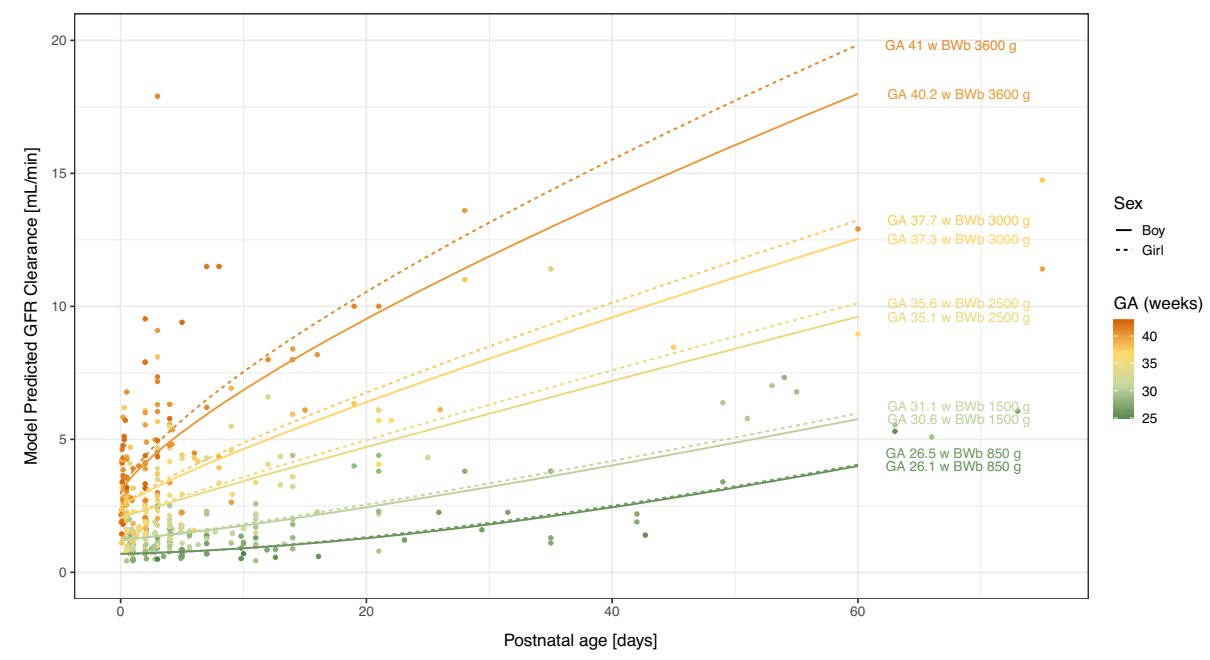

Fig. 4 Glomerular filtration rate (GFR) versus postnatal age simulated from the final optimized model in typical neonates with different birthweight $(\mathrm{BWb}, \mathrm{g})$ and the corresponding gestational age (GA, weeks) generated from Fenton growth charts (26) for boys (solid line) and girls (dashed line). The symbols are the observed inulin clearance values (30-41)

(Fig. 4). However, our study also showed that for preterm neonates with $\mathrm{GA}<34$ weeks the maturation rate of GFR is gradually increasing while in neonates with GA > 34 weeks, the maturation rate of GFR is gradually slowing down. As there were very limited data of inulin clearance after 30 days of PNA, whether and when the preterm neonates will catch up afterwards with their term peers is still unknown.

The GFR maturation trend shown in this study underlines the importance of BWb or GA and PNA-based dosing of primarily renally cleared drugs. In order to achieve a comparable exposure among all neonates, different dosing regimens should be used for different $\mathrm{BWb}$ or GA and PNA groups. These BWb or GA and PNA-based dosing strategies have already been suggested for amikacin, gentamicin, and tobramycin $(53,54)$. This should also be considered for other drugs primarily cleared by glomerular filtration that have not yet been investigated sufficiently.

The inulin clearance in neonatal population showed large variability (Fig. 1). Although part of this have been explained by $\mathrm{BW}, \mathrm{GA}$, and PNA, there is still unexplained variability that is possibly due to the different health conditions of included patients ( $31 \%$ inter-individual variability), as well as the different assay and measurement methodologies of inulin used in different studies (19\% inter-study variability).

Our study has some limitations. First, as not all papers reported complete individual demographic information, some values were imputed, which might have impacted our model comparisons and parameter estimates. However, as our study has tried to reduce bias as much as possible by imputing missing demographic values based on the known relationship between covariates in neonates (e.g., growth charts of $\mathrm{BW}$ and GA, WT and PNA), we believe this impact is limited. Moreover, it cannot be excluded that the individuals included in this study do not represent the overall (healthy) neonatal population, because not all the included subjects were healthy and we were not able to detect the influences of recorded disease. Next, the available data on inulin clearance in term neonates with PNA > 30 days is limited (Fig. 1). Therefore, the predictions for PNA > 30 days might be less accurate and require further validation. Finally, our study intentionally only collected data up to 90 days, which prevented us to investigate the connection of GFR predictions from neonates to older children and the adults.

\section{CONCLUSION}

To predict GFR maturation in (pre)term neonates and young infants, and using $\mathrm{CL}_{\text {inulin }}$ data as reference, the De Cock 2014a (4) model with CLp adjusted for $\mathrm{CL}_{\text {inulin }}$ had the best performance across GA and PNA. This was followed by the Rhodin 2009 model (3), which, however, displayed biased predictions with increasing PNA. Based on these results, we concluded that neonatal GFR maturation models require a distinction between pre- and postnatal GFR maturation. Prenatal GFR maturation in (pre)term neonates is determined by $\mathrm{BWb}$, with a higher $\mathrm{BWb}$ indicating a higher GFR at birth. To capture the varying postnatal GFR maturation rates, we included GA as determinant for PNA-dependent maturation in the optimized GFR maturation model, which can subsequently be used to predict clearance in renally cleared drugs across the heterogeneous population of (pre)term neonates and young infants.

\section{SUPPLEMENTARY INFORMATION}

The online version contains supplementary material available at https://doi.org/10.1208/s12248-022-00688-z.

\section{ACKNOWLEDGEMENTS}

The authors would like to thank Kinga N. Fiebig for reviewing the codes of this paper, and Aline G.J. Engbers for providing inputs during discussion. 


\section{AUTHOR CONTRIBUTION}

Y.W, K.A, E.H.J.K, C.A.J.K, and S.V were involved in study design, acquisition of data, performing the analysis, data interpretation, drafting, revising the manuscript, and final approval. R.B.F and S.H.P.S were involved in study design, interpretation of data, drafting, and revising the manuscript and final approval.

\section{FUNDING}

No funding has been received for this study.

\section{DECLARATIONS}

Conflict of Interest The authors declare no conflict of interest.

\section{REFERENCES}

1. Salem F, Johnson TN, Hodgkinson ABJ, Ogungbenro K, Rostami-Hodjegan A. Does "Birth" as an Event impact maturation trajectory of renal clearance via glomerular filtration? Reexamining data in preterm and full-term neonates by avoiding the creatinine bias. J Clin Pharmacol. 2021;61(2):15971. https://doi.org/10.1002/jcph.1725.

2. Johnson TN, Rostami-Hodjegan A, Tucker GT. Prediction of the clearance of eleven drugs and associated variability in neonates, infants and children. Clin Pharmacokinet. 2006;45(9):931-56. https://doi.org/10.2165/00003088-20064509000005.

3. Rhodin MM, Anderson BJ, Peters AM, Coulthard MG, Wilkins B, Cole M, Chatelut E, Grubb A, Veal GJ, Keir MJ, Holford NHG. Human renal function maturation: a quantitative description using weight and postmenstrual age. Pediatr Nephrol. 2009;24(1):67-76. https://doi.org/10.1007/s00467-008-0997-5.

4. De Cock RF, Allegaert K, Sherwin CM, Nielsen EI, de Hoog M, van den Anker JN, et al. A neonatal amikacin covariate model can be used to predict ontogeny of other drugs eliminated through glomerular filtration in neonates. Pharm Res. 2014;31(3):754-67. https://doi.org/10.1007/s11095-013-1197-y.

5. De Cock RF, Allegaert K, Brussee JM, Sherwin CM, Mulla H, de Hoog M, et al. Simultaneous pharmacokinetic modeling of gentamicin, tobramycin and vancomycin clearance from neonates to adults: towards a semi-physiological function for maturation in glomerular filtration. Pharm Res. 2014;31(10):2643-54. https://doi.org/10.1007/s11095-014-1361-z.

6. Mahmood I, Staschen CM. Prediction of human glomerular filtration rate from preterm neonates to adults: evaluation of predictive performance of several empirical models. AAPS J. 2016;18(2):445-54. https://doi.org/10.1208/s12248-016-9868-3.

7. Anderson BJ, Holford NHG. Negligible impact of birth on renal function and drug metabolism. Paediatr Anaesth. 2018;28(11):1015-21. https://doi.org/10.1111/pan.13497.

8. Schreuder MF, Bueters RR, Allegaert K. The interplay between drugs and the kidney in premature neonates. Pediatr Nephrol (Berlin, Germany). 2014;29(11):2083-91. https://doi.org/10.1007/ s00467-013-2651-0.

9. Kuppens M, George I, Lewi L, Levtchenko E, Allegaert K. Creatinaemia at birth is equal to maternal creatinaemia at delivery: does this paradigm still hold? J Matern Fetal Neonatal Med. 2012;25(7):978-80. https://doi.org/10.3109/ 14767058.2011.602144.

10. Guignard JP, Drukker A. Why do newborn infants have a high plasma creatinine? Pediatrics. 1999;103(4):e49. https://doi.org/ 10.1542/peds.103.4.e49.
11. Abitbol CL, Seeherunvong W, Galarza MG, Katsoufis C, Francoeur D, Defreitas M, et al. Neonatal kidney size and function in preterm infants: what is a true estimate of glomerular filtration rate? J Pediatr. 2014;164(5):1026-31.e2. https://doi.org/10.1016/j.jpeds.2014.01.044.

12. Pottel H. Measuring and estimating glomerular filtration rate in children. Pediatr Nephrol (Berlin, Germany). 2017;32(2):24963. https://doi.org/10.1007/s00467-016-3373-x.

13. Schwartz GJ, Furth SL. Glomerular filtration rate measurement and estimation in chronic kidney disease. Pediatr Nephrol (Berlin, Germany). 2007;22(11):1839-48. https://doi.org/ 10.1007/s00467-006-0358-1.

14. Soveri I, Berg UB, Björk J, Elinder CG, Grubb A, Mejare I, Sterner G, Bäck SE, SBU GFR Review Group. Measuring GFR: a systematic review. Am J Kidney Dis. 2014;64(3):411-24. https://doi.org/10.1053/j.ajkd.2014.04.010.

15. Piepsz A, Pintelon H, Ham HR. Estimation of normal chromium-51 ethylene diamine tetra-acetic acid clearance in children. Eur J Nucl Med. 1994;21(1):12-6. https://doi.org/ 10.1007/bf00182300.

16. Holliday MA, Heilbron D. al-Uzri A, Hidayat J, Uauy R, Conley S, et al. Serial measurements of GFR in infants using the continuous iothalamate infusion technique. Southwest Pediatric Nephrology Study Group (SPNSG). Kidney Int. 1993;43(4):893-8. https://doi.org/10.1038/ki.1993.125.

17. Koren G, James A, Perlman M. A simple method for the estimation of glomerular filtration rate by gentamicin pharmacokinetics during routine drug monitoring in the newborn. Clin Pharmacol Ther. 1985;38(6):680-5. https://doi.org/10.1038/ clpt.1985.245.

18. De Cock RF, Allegaert K, Schreuder MF, Sherwin CM, de Hoog M, van den Anker JN, et al. Maturation of the glomerular filtration rate in neonates, as reflected by amikacin clearance. Clin Pharmacokinet. 2012;51(2):105-17. https://doi.org/10.2165/ 11595640-000000000-00000.

19. Solhaug MJ, Bolger PM, Jose PA. The developing kidney and environmental toxins. Pediatrics. 2004;113(4 Suppl):1084-91.

20. Charlton JR, Springsteen CH, Carmody JB. Nephron number and its determinants in early life: a primer. Pediatr Nephrol (Berlin, Germany). 2014;29(12):2299-308. https://doi.org/ 10.1007/s00467-014-2758-y.

21. Abitbol CL, DeFreitas MJ, Strauss J. Assessment of kidney function in preterm infants: lifelong implications. Pediatr Nephrol (Berlin, Germany). 2016;31(12):2213-22. https:// doi.org/10.1007/s00467-016-3320-x.

22. Chen N, Aleksa K, Woodland C, Rieder M, Koren G. Ontogeny of drug elimination by the human kidney. Pediatr Nephrol (Berlin, Germany). 2006;21(2):160-8. https://doi.org/10.1007/ s00467-005-2105-4.

23. Iacobelli S, Guignard J-P. Maturation of glomerular filtration rate in neonates and infants: an overview. Pediatr Nephrol. 2020;36:1439-46. https://doi.org/10.1007/s00467-020-04632-1.

24. Anchieta LM, Xavier CC, Colosimo EA, Souza MF. Weight of preterm newborns during the first twelve weeks of life. Brazilian journal of medical and biological research $=$. Revista brasileira de pesquisas medicas e biologicas. 2003;36(6):761-70. https:// doi.org/10.1590/s0100-879x2003000600012.

25. WHO: WHO Weight-for-age growth charts. https:// www.who.int/tools/child-growth-standards/standards/weightfor-age Accessed.

26. Fenton TR, Kim JH. A systematic review and meta-analysis to revise the Fenton growth chart for preterm infants. BMC Pediatr. 2013;13:59. https://doi.org/10.1186/1471-2431-13-59.

27. Abduljalil K, Pan X, Pansari A, Jamei M, Johnson TN. A preterm physiologically based pharmacokinetic model. Part I: Physiological Parameters and Model Building. Clin Pharmacokinet. 2020;59(4):485-500. https://doi.org/10.1007/ s40262-019-00825-6.

28. Haycock GB, Schwartz GJ, Wisotsky DH. Geometric method for measuring body surface area: a height-weight formula validated in infants, children, and adults. J Pediatr. 1978;93(1):62-6. https://doi.org/10.1016/s0022-3476(78)806015.

29. Ludden TM, Beal SL, Sheiner LB. Comparison of the Akaike information criterion, the Schwarz criterion and the 
F test as guides to model selection. J Pharmacokinet Biopharm. 1994;22(5):431-45. https://doi.org/10.1007/ BF02353864.

30. Coulthard MG. Maturation of glomerular filtration in preterm and mature babies. Early Hum Dev. 1985;11(3-4):281-92. https://doi.org/10.1016/0378-3782(85)90082-9.

31. Oh W, Oh MA, Lind J. Renal function and blood volume in newborn infant related to placental transfusion. Acta Paediatr. 1966;55(2):197-210. https://doi.org/10.1111/j.16512227.1966.tb15226.x

32. Leake RD, Trygstad CW. Glomerular filtration rate during the period of adaptation to extrauterine life. Pediatr Res. 1977;11(9 Pt 1):959-62. https://doi.org/10.1203/00006450-197709000-00005.

33. Leake RD, Trygstad $\mathrm{CW}$, Oh W. Inulin clearance in the newborn infant: relationship to gestational and postnatal age. Pediatr Res. 1976;10(8):759-62. https://doi.org/10.1203/ 00006450-197608000-00013.

34. Guignard JP, Torrado A, Da Cunha O, Gautier E. Glomerular filtration rate in the first three weeks of life. J Pediatr. 1975;87(2):268-72. https://doi.org/10.1016/s0022-3476(75)806007.

35. van der Heijden AJ, Grose WF, Ambagtsheer JJ, Provoost AP, Wolff ED, Sauer PJ. Glomerular filtration rate in the preterm infant: the relation to gestational and postnatal age. Eur J Pediatr. 1988;148(1):24-8. https://doi.org/10.1007/bf00441807.

36. Robinson D, Weiner CP, Nakamura KT, Robillard JE. Effect of intrauterine growth retardation on renal function on day one of life. Am J Perinatol. 1990;7(4):343-6. https://doi.org/10.1055/s2007-999519.

37. Hansen NB, Oh W, LaRochelle F, Stonestreet BS. Effects of maternal ritodrine administration on neonatal renal function. $\mathrm{J}$ Pediatr. 1983;103(5):774-80. https://doi.org/10.1016/s00223476(83)80484-3.

38. Broberger U. Determination of glomerular filtration rate in the newborn comparison between results obtained by the single injection technique without collection of urine and the standard clearance technique. Acta Paediatr. 1973;62(6):625-8. https:// doi.org/10.1111/j.1651-2227.1973.tb17076.x.

39. Barnett HL, Hare WK, et al. Influence of postnatal age on kidney function of premature infants. Proceedings of the Society for Experimental Biology and Medicine Society for Experimental Biology and Medicine (New York, NY). 1948;69(1):55-7. https://doi.org/10.3181/00379727-69-16616p.

40. Brodehl J, Gellissen K. Endogenous renal transport of free amino acids in infancy and childhood. Pediatrics. 1968;42(3):395-404.

41. Fawer CL, Torrado A, Guignard JP. Maturation of renal function in full-term and premature neonates. Helvetica Paediatrica Acta. 1979;34(1):11-21.

42. Cristea S, Krekels EHJ, Allegaert K, Knibbe CAJ. The predictive value of glomerular filtration rate-based scaling of pediatric clearance and doses for drugs eliminated by glomerular filtration with varying protein-binding properties. Clin Pharmacokinet. 2020;59(10):1291-301. https://doi.org/10.1007/ s40262-020-00890-2.
43. McNamara PJ, Alcorn J. Protein binding predictions in infants. AAPS Pharm Sci. 2002;4(1):E4. https://doi.org/10.1208/ ps040104.

44. Cuzzolin L, Fanos V, Pinna B, di Marzio M, Perin M, Tramontozzi $\mathrm{P}$, et al. Postnatal renal function in preterm newborns: a role of diseases, drugs and therapeutic interventions. Pediatr Nephrol (Berlin, Germany). 2006;21(7):931-8. https://doi.org/10.1007/s00467-006-0118-2.

45. Brion N, Barge J, Godefroy I, Dromer F, Dubois C, Contrepois A, Carbon C. Gentamicin, netilmicin, dibekacin, and amikacin nephrotoxicity and its relationship to tubular reabsorption in rabbits. Antimicrob Agents Chemother. 1984;25(2):168-72. https://doi.org/10.1128/aac.25.2.168.

46. Contrepois A, Brion N, Garaud JJ, Faurisson F, Delatour F, Levy JC, Deybach JC, Carbon C. Renal disposition of gentamicin, dibekacin, tobramycin, netilmicin, and amikacin in humans. Antimicrob Agents Chemother. 1985;27(4):520-4. https://doi.org/10.1128/aac.27.4.520.

47. Hughson M, Farris AB 3rd, Douglas-Denton R, Hoy WE, Bertram JF. Glomerular number and size in autopsy kidneys: the relationship to birth weight. Kidney Int. 2003;63(6):2113-22. https://doi.org/10.1046/j.1523-1755.2003.00018.x.

48. Hinchliffe SA, Lynch MR, Sargent PH, Howard CV, Van Velzen $D$. The effect of intrauterine growth retardation on the development of renal nephrons. $\mathrm{Br} \mathrm{J}$ Obstet Gynaecol. 1992;99(4):296-301. https://doi.org/10.1111/j.14710528.1992.tb13726.x.

49. Aperia A, Broberger O, Elinder G, Herin P, Zetterström R. Postnatal development of renal function in pre-term and fullterm infants. Acta Paediatr Scand. 1981;70(2):183-7. https:// doi.org/10.1111/j.1651-2227.1981.tb05539.x.

50. Bueva A, Guignard JP. Renal function in preterm neonates. Pediatr Res. 1994;36(5):572-7. https://doi.org/10.1203/00006450199411000-00005.

51. Gallini F, Maggio L, Romagnoli C, Marrocco G, Tortorolo G. Progression of renal function in preterm neonates with gestational age $<$ or $=32$ weeks. Pediatr Nephrol (Berlin, Germany). 2000;15(1-2):119-24. https://doi.org/10.1007/s004670000356.

52. Sutherland MR, Gubhaju L, Moore L, Kent AL, Dahlstrom JE, Horne RS, et al. Accelerated maturation and abnormal morphology in the preterm neonatal kidney. J Am Soc Nephrol. 2011;22(7):1365-74. https://doi.org/10.1681/asn.2010121266.

53. Valitalo PA, van den Anker JN, Allegaert K, de Cock RF, de Hoog M, Simons SH, et al. Novel model-based dosing guidelines for gentamicin and tobramycin in preterm and term neonates. J Antimicrob Chemother. 2015;70(7):2074-7. https:// doi.org/10.1093/jac/dkv052.

54. Smits A, De Cock RF, Allegaert K, Vanhaesebrouck S, Danhof M, Knibbe CA. Prospective evaluation of a model-based dosing regimen for amikacin in preterm and term neonates in clinical practice. Antimicrob Agents Chemother. 2015;59(10):6344-51. https://doi.org/10.1128/aac.01157-15.

Publisher's NoteSpringer Nature remains neutral with regard to jurisdictional claims in published maps and institutional affiliations. 